\title{
The Intrapersonal and Interpersonal Processes of Fear of Recurrence Among Cervical Cancer Survivors - A Qualitative Research.
}

Yaira Hamama-Raz ( $\nabla$ yairahr@ariel.ac.il )

Ariel University https://orcid.org/0000-0002-0496-6414

Shiri Shinan-Altman

Bar-llan University

Inbar Levkovich

Oranim Academic College of Education

\section{Research Article}

Keywords: cervical cancer, survivors, fear of recurrence, qualitative research

Posted Date: August 23rd, 2021

DOI: https://doi.org/10.21203/rs.3.rs-771323/v1

License: (c) (i) This work is licensed under a Creative Commons Attribution 4.0 International License.

Read Full License 


\section{Abstract}

Objective: Cervical cancer often takes an emotional and mental toll on the affected woman. Fear of cancer recurrence was identified as one of the most prominent unmet needs in patients and survivors. The present study sought to explore meaning of fear of cancer recurrence among cervical cancer survivors owing to the paucity of studies regarding this population.

Methods: In this qualitative research, semi structured interviews conducted with 15 cervical cancer survivors. Interviewees' mean age was 41.33 years (range 34-47 years) and time since diagnosis ranged from six months to seven years (mean - 3.1 years).

Results: Three central themes emerged that represent intrapersonal and interpersonal processes that begin with relief from fears of cancer recurrence, alongside acknowledgement of being no longer resilient, representing the intrapersonal level. Next, an interpersonal level that included mutual fears shared by the interviewee and her partner, reflected either by coping together or coping alone. Finally, fear of recurrence became a combination of intrapersonal and interpersonal processes manifested by the greatest fear death, expressed by both the interviewee and her family members.

Conclusions: The present findings revealed that the meaning of fear of cancer recurrence represents intrapersonal and interpersonal processes encompassing three factors - uncertainty, social-cognitive processing and death anxiety. Accordingly, potential psycho-social treatment options could be tailored specific to the dominance of these factors for cervical cancer survivor.

\section{Introduction}

Cervical cancer is the fourth most common cancer in women [1]. Surgery, radiation and chemotherapy represent proven-effective treatment for cervical cancer. However, up to one third of patients will develop a progressive or recurrent disease [2], which might give rise to fear of cancer recurrence.

Fear of cancer recurrence is defined as: "Fear, worry or concern relating to the possibility that cancer will come back or progress"[3, p.3266]. Although, some degree of FCR may be adaptive in terms of alerting the patient to signs of new or recurring cancer and encouraging positive health behaviors [4], clinical levels of FCR are associated with psychological comorbidity - anxiety and depression $[5,6]$ reduced quality of life [7] increased health-care costs due to more frequent emergency room visits [8], and avoidance of tests to identify recurrence in time [2]. Thus, Leeson et al. [9] highlighted the primary importance of addressing FCR among gynecological cancer survivors.

Only one quantitative research has been conducted to date regarding the meaning of FCR among cervical cancer survivors [5], which revealed that the three greatest fears reported by participants were what would happen to their family; pain; and disease progression (items from the Fear of Progression Questionnaire [10]). Owing to the paucity of studies regarding the meaning of FCR among cervical cancer survivors, we undertook the invitation [11] to conduct a qualitative study to gain a deeper understanding of FCR among 
cervical cancer survivors. A better understanding of FCR in cervical cancer survivors can help clinicians manage this problem effectively.

\section{Methods}

\subsection{Research methodology}

Qualitative methodology in a phenomenological paradigm was used, to facilitate examination of the experiences and voices of participants as they choose to express them, and thus gain insights that give meaning to multi-dimensional phenomena [12].

\subsection{Participants}

Qualitative research is based on small, purposive, non-representative

samples [13]. The current study included 15 qualitative interviews with women diagnosed with cervical cancer. The final sample size was determined according to the theoretical saturation principle. Hence, the interviews continued until no new information emerged [13]. Interviewees' mean age was 41.33 years (range 34-47 years), who were 31-46 years old when diagnosed with cervical cancer. Most were married $(n=13)$ and had children $(n=12)$ when they were diagnosed with cervical cancer. Their illness stage was $\mathrm{I}-\mathrm{Il}$ treated with surgery followed by radiation therapy (internal + external) $(\mathrm{n}=1)$ or chemoradiation $(\mathrm{n}=$ 14). Time since diagnosis ranged from six months to seven years (mean - 3.1 years). The variation in demographic variables among participants provided important breadth on the topic of study [14]. Detailed information for participants appears in Table 1. 
Table 1

The study participants characteristics

\begin{tabular}{|c|c|c|c|c|c|}
\hline $\begin{array}{l}\text { Participant's } \\
\text { Number }\end{array}$ & $\begin{array}{l}\text { Age when } \\
\text { diagnosed }\end{array}$ & Family status & $\begin{array}{l}\text { No. of } \\
\text { children }\end{array}$ & $\begin{array}{l}\text { Years since } \\
\text { last } \\
\text { treatment }\end{array}$ & $\begin{array}{l}\text { Types of } \\
\text { treatments }\end{array}$ \\
\hline 1 & 38 & married & 0 & 1.5 years & $\begin{array}{l}\text { Surgery }+ \\
\text { chemoradiation }\end{array}$ \\
\hline 2 & 37 & married & 2 & 3.5 years & $\begin{array}{l}\text { Surgery }+ \\
\text { chemoradiation }\end{array}$ \\
\hline 3 & 38 & married & 2 & 3 years & $\begin{array}{l}\text { Surgery }+ \\
\text { chemoradiation }\end{array}$ \\
\hline 4 & 38 & married & 0 & 5 years & $\begin{array}{l}\text { Surgery }+ \\
\text { chemoradiation }\end{array}$ \\
\hline 5 & 34 & married & 2 & 3 years & $\begin{array}{l}\text { Surgery }+ \\
\text { chemoradiation }\end{array}$ \\
\hline 6 & 40 & married & 0 & 4.5 years & $\begin{array}{l}\text { Surgery }+ \\
\text { chemoradiation }\end{array}$ \\
\hline 7 & 42 & married & 3 & 5 years & $\begin{array}{l}\text { Surgery + } \\
\text { radiation }\end{array}$ \\
\hline 8 & 41 & married & 3 & 5 years & $\begin{array}{l}\text { Surgery }+ \\
\text { chemoradiation }\end{array}$ \\
\hline 9 & 46 & $\begin{array}{l}\text { divorced (now in a } \\
\text { committed relationship) }\end{array}$ & 2 & 2.5 years & $\begin{array}{l}\text { Surgery }+ \\
\text { chemoradiation }\end{array}$ \\
\hline 10 & 45 & married & 2 & 7 years & $\begin{array}{l}\text { Surgery }+ \\
\text { chemoradiation }\end{array}$ \\
\hline 11 & 47 & married & 1 & 1 year & $\begin{array}{l}\text { Surgery }+ \\
\text { chemoradiation }\end{array}$ \\
\hline 12 & 44 & married & 2 & 0.5 year & $\begin{array}{l}\text { Surgery }+ \\
\text { chemoradiation }\end{array}$ \\
\hline 13 & 43 & married & 2 & 0.5 year & $\begin{array}{l}\text { Surgery }+ \\
\text { chemoradiation }\end{array}$ \\
\hline 14 & 44 & married & 2 & 2.5 years & $\begin{array}{l}\text { Surgery }+ \\
\text { chemoradiation }\end{array}$ \\
\hline 15 & 43 & divorce & 3 & 2 years & $\begin{array}{l}\text { Surgery }+ \\
\text { chemoradiation }\end{array}$ \\
\hline
\end{tabular}

\subsection{Instrument}

Data were gathered using semi-structured in-depth interviews. This is a flexible framework for examining the meaning of behaviors, feelings, beliefs and perceptions [12]. An interview guide was constructed using a funnel approach [15] starting from broad questions followed by more detailed ones. The study 
was based on secondary analysis that aimed to examine a specific aspect of the data [16], based on four FCR related questions: "Are you busy thinking about the possibility of recurrence of the disease? If so, what is the content of these thoughts?"; "How have these thoughts affected your life?"; "What are the feelings and thoughts when you raise these concerns with your partner?" When needed, clarifying questions were used such as "Can you please elaborate your discussion regarding your fears?" and "Please tell me more about your partner's FCR." Finally, selected demographic questions were included to situate the respondents in a sociocultural context.

\subsection{Data collection and Ethical Considerations}

This is part of a larger qualitative study about women who recovered from cervical cancer. Data were collected between November 2020 and February 2021. The present study and consent procedure were approved by the second author's University's Ethics Committee (Approval no. 112003). Participants were recruited through internet forums and websites dealing with cervical cancer, and through social media outlets (Facebook pages focusing on cervical cancer). The inclusion criteria were: Hebrew speakers, being above 18 years, diagnosis with cervical cancer and being completed adjuvant therapy (chemotherapy and/or radiation) at least 6 months prior to study initiation, A brief explanation of the general research aims was provided followed by informed consent. Participants were informed of psychological support that would be available to them if they felt emotional distress at any point during the study. None made use of this offer.

Due to lockdown requirements owing to COVID-19, all interviews were conducted by the three authors (separately), using the video-conference platform Zoom. Each participant received a private email invitation.

With participant oral permission, all interviews were audio and video recorded to allow access to nonverbal cues such as facial expressions, eye contact, or body motions. Field notes were collected by the researchers during the interviews because they provide a rich source of information as participants describe their experiences during data collection. Confidentiality was assured by numbering each interview and removing identifying information from the transcripts. All audio recordings and transcripts were saved on a password-protected computer with access only for the researchers. The interviews were conducted in Hebrew and lasted 60-80 minutes. We concluded the recruitment process when we reached content saturation and no new data in the form of thematic categories emerged from the interviews.

\subsection{Data analysis}

Content analysis [17] was used by each of the three authors, which consisted of: 1 . Open coding: the researchers independently read each interview transcript line by line, jotting down notes to identify initial units of meaning (categories) emerging from the interviews. Differences between coders were resolved through discussion until a consensus was reached. 2. Axial coding: the researchers gradually detected associations between themes related to context and content. They compared all interviews to consolidate meaning and named the themes. Next, the researchers examined interrelationships among the initial codes and sorted them into higher-order theoretical codes. 3. Integration: core themes that emerged from 
the data were reordered conceptually and placed into context, enabling analysis and integration of large amounts of data and generation of abstractions and interpretations $[12,18]$.

\section{Results}

Exploring the meaning of FCR among cervical cancer survivors produced three central themes that are illustrated in Fig. 1.

Theme 1- " No longer resilient"- from relief from fear to fear for myself and my loved ones.

Interviewees described how cancer shattered the sense of resilience they had previously felt. However, some interviewees described that FCR and emotional reactions somewhat ameliorated over time. Some described more intense fear in the first year.

In the first year I met it [FCR] with every breath, today it is much better... I had sores in the mouth and legs, just like a one-on-one childhood illness. (Interviewee 2).

Some interviewees felt that there was no guarantee, anyone could get cancer. Even though time had past since their initial diagnosis, even mild palpitations are immediately translated into a deadly disease. Interviewee 15 described the transition from the feeling of being healthy to a feeling of being a hypochondriac who is constantly concerned with her health.

I was an athletic girl and today it's hard for me. Maybe I'm scared too. I always knew I was a healthy woman, I never thought I would go through something like that. Today I'm scared, even if I catch cold, I'm scared. (Interviewee 15).

In addition, interviewees described difficulties in performing follow-up medical tests as it increases the tension and stress regarding the possibility of disease recurrence. Some expressed a desire to be closely monitored in order to know that there is no cancer in the body.

I have constant fears... I perform a CT scan every three to five months .... and then suddenly they tell me, 'You have something on your ribs.' 'Did you break a rib?' 'But I did not break, ..., they instilled in me the fear that maybe it came back somewhere else. (Interviewee 5).

.. I go with huge fear to follow-up tests.... Anxieties from here to there... the month that I'm waiting for PET CT and after that while I am waiting for the results, it takes seven years off of my life. (Interviewee 6).

The understanding and ensuing fear of a possibility that the disease would return was transferred to some of the interviewees non-verbally by the medical staff. These interviewees described a sense of deception and frustration.

"I was sure that when I finished the treatments that that's it... no more.....After they took out my uterus I said to my doctors: 'that's it'? 'I will not have it again, right?' However, then I saw a discomfort in the doctor's body language, and I realized that it could also be caught on any other tissue " (Interviewee 9). 
A common means for coping with fear of recurrence was taking antidepressants. Some described dependence on the drug and argued that without it, fears of the disease would surely have surfaced.

I just did a CT scan and it's clean and normal, but there was something in the thyroid that they saw which was abnormal...... if I was without an antidepressant, I would have been more anxious in general and in particular regarding the possibility of reoccurrence [of the disease] (Interviewee 7).

The perpetual fear has an existential effect even on the health of their loved ones. Interviewees described that each symptom and illness of their children caused alarm. Every pain, even mild and common, suggests potential cancer and the threat is unbearable.

I lost my medical confidence. Today I am anxious about everything. If my son has a leg pain, then a I immediately take him to a doctor because God knows what will happen. (Interviewee 15).

Theme 2- "To be afraid in two" - me and my partner in the shadow of fear of recurrence.

Coping with the fear of recurrence of the disease was described by some interviewees as couple coping, in which there was room for a dialogue about fears and concerns.

He was really stressed but he was also really supportive, there were also ups and downs but we talked about everything including fears and concerns.... However, there is no doubt that he is still afraid that there will be a second round of all this (Interviewee 12).

Interviewees described their partner's resources that enabled them to cope with fear of recurrence. For example, the spouse's internal resource of optimism enabled relief from fear of disease recurrence as described by Interviewee 8 .

My husband is very optimistic, he really strengthens me, he constantly conveys that he is not afraid of anything. He keeps telling me that when we are together, nothing can beat us, and it works.

Indeed, another resource in a relationship that can alleviate fear is the feeling of togetherness. The spouse of Interviewee 4 gave her the feeling that she is not alone:

He always says, 'We go through this together.'... if there was any small pain, he would say let's call to check, let's go to the doctor.

In contrast, some interviewees described how their partners did not allow communication about the disease and fears that accompanied the possibility of disease recurrence. They felt great frustration and loneliness at not being able to talk to them about the fears. Each was closed in his/her own feelings.

There is a fear that the disease will return... I am sure my husband is also afraid. But he does not talk about these feelings and I have a hard time with it. He leaves me alone. He shows no emotion, but he has that fear (Interviewee 11). 
Theme 3 - Cancer equals death - "And what if the disease comes back and I will die?"

Some interviewees expressed the perception of the temporality and fragility of life in facing the possibility of recurrence of the disease. They feared and described their existential fear of dying from cancer. At the same time, some interviewees argued that although rationally they understood that the probability of dying from their disease was low, the fear remains.

I'm afraid to die if the cancer comes back... as if I have a limited time left to live... unfortunately today I know that you can die...on the other hand I understand that the probability that I will die from this cancer is relatively low ... rationally I understand and still when I think about it - I am afraid (Interviewee 1).

Another fear that some interviewees described is that if the disease returns, it will be more violent than before, and they will not be able to cope with it physically and mentally or survive it the next time.

I'm afraid to cope with the disease,... if the disease comes back again it will be fatal. It scares me (Interviewee 3).

The familiarity of some of the interviewees with recurrent cancer among people in their surrounding makes disease recurrence a real and stressful possibility. Interviewee 14 said that she is not afraid of harsh and exhausting treatments. The only thing she is afraid of is death.

The fear is not about treatment or further resection. No, no. The fear is of dying because cancer is equal to death ... what if I die of the disease....

The fear of dying was also expressed by close family members.

One day he suddenly woke me up at noon. He had tears in his eyes, 'I love you', he said. I asked him what happened? He told me that he thought I would die if the disease came back. We cried together (Interviewee 5).

The fear of death following the possibility of recurrence of the disease was described not only among interviewees' spouses but also among their children.

Mom could you die from cancer? My older daughter often asks (age 12). She says to me that it is impossible to live without a mother, children cannot live without a mother. I want to protect her so much... (Interviewee 6).

One of the children's ways to cope with fears that their mother's disease would reoccur was through black humor as described by Interviewee 13.

Don't ask what nickname one of the girls gave me, she calls me 'dying' (laughs). At first I was shocked but then I realized she had to channel her fears that the disease would reoccur (Interviewee 13).

\section{Discussion}


In the present study's findings indicated that the meaning of FCR among cervical cancer survivors is dynamic and ranged from relief of fear of recurrence to fear of dying. It includes intra and interpersonal processes beginning with intrapersonal experience, proceeding to interpersonal experience, and ending with combination of intra and interpersonal processes.

The first theme "No longer resilient - from relief from fear to fear for myself and my loved ones" supported quantitative studies which revealed that FCR in different degrees during survivorship have been reported, regardless of the length of the survivorship [e.g.,2, 19). In addition, it seemed that external triggers such as follow-up appointments and illness of a child aroused anxiety and a strong sense of distress. Indeed, Simard et al. [6] identified strong relationships between distress and FCR. Moreover, according to the Uncertainty in IIIness Model [20], perception of uncertainty in illness occurs when the meaning of an event cannot be understood because of its complexity, ambiguity, or mismatch between expectation and the realistic world. In addition, illness uncertainty may also affect stress appraisal, which can in turn affect coping strategies. Thus, it might be that cervical cancer survivors' level of uncertainty affects their stress appraisal, which mostly consists of harm and threat, and less of challenges. This is intensified by some of their healthcare providers that through their body language imply that medical treatment does not guarantee full recovery. Thus, it was not surprising that feeling "no longer resilient" emerged, leading to responses of depression and anxiety which required antidepressant medication.

Regarding the second theme "To be afraid in two" - me and my partner in the shadow of fear of recurrence", our findings indicate that the presence of a partner during the disease treatments and over the survivorship phase may affect FRC, which in turn might impact the level of distress. In line with this notion, the social-cognitive processing model [21] argues that the social environment can either enhance or inhibit cognitive processing of the cancer experience. Negative social responses to attempts to discuss the cancer experience (i.e., social constraints) may lead to avoidance of thinking or talking about cancer, which, in turn, may inhibit cognitive processing and exacerbate emotional distress [22]. However, positive social responses may allow open discussion which, in turn may enhance cognitive processing and decrease emotional destress in accordance with the stress-buffering effect of social support [23].

Accordingly, Myers et al. [24] found among women diagnosed with gynecologic cancer that not sharing concerns and negative responses from family and friends, were related to increased FCR and, in turn, increased cancer-specific stress. Likewise, Wijayanti et al. [25] found that among gynecological cancer survivors, those with higher social support were more likely to experience lower levels of FCR. Moreover, several quantitative studies noted that spouses of cancer survivors are typically found to have greater levels of FCR than patients themselves [6] and patient and spouse FCR scores have been found to correlate within-dyad [26,27]. Given the above, our findings support the importance of dynamic interpersonal contexts of FCR and highlight the meaning of "to be afraid in two" with regard to FCR, that needs to be met when considering how to regulate FCR levels.

Finally, the third theme "Cancer equals death - And what if the disease comes back and I will die?" highlights the fear of dying. Indeed, fear of death as a component of FCR was noted in a study conducted 
among breast cancer patients [28] suggesting that women with all levels of FCR identified fear of death as their worst fear. Similarly, Tang et al. [29], found among cancer patients that their levels of fear of disease relapse, had detrimental effects on their levels of death anxiety. These two studies support Sharpe et al.'s [30] call to investigate the role that death anxiety has in FCR "because the way in which these fears may best be addressed is likely to differ and hence the actual worst fear should always be assessed if FCR is present" [p. 256]. According to the terror management theory (TMT) [31] the natural human instinct for self-preservation combined with a self-awareness of mortality creates the potential for debilitating levels of anxiety that need to be managed in order to function. Death awareness produces existential anxiety that has been reflected through FCR. Moreover, our findings indicate that death anxiety reflected by FCR is also felt by other members of the cancer survivor's family, which might intensify the survivor's FCR, suggesting intra and interpersonal processes that FCR represents.

Several limitations should be noted. First, due to the small number of participants that were interviewed, and the cross-sectional design, findings should be considered as a tentative basis for further investigation. Longitudinal research on FCR required to gain a better understanding of this concept. In addition, most of the participants in the current study were short-term survivors (mean 3.1 years). Perhaps longer-term cervical cancer survivors might reveal different meanings of FCR. It should be noted that younger survivors and women are more prone to experiencing higher levels of FCR [6]. Thus, future qualitative studies should examine the meaning of FCR with older survivor. Likewise, other family members (spouses, children,) and different cultures should be studied, in order to place the knowledge gained in this study in a broader context.

With regard to implications for practice, the present findings suggest that the meaning of FCR encompasses three theories - the uncertainty in illness theory, social-cognitive processing theory, and terror management theory. These theories could help to further our understanding of FCR and inform the development of personalized potential treatment options specific to FCR according to the dominance of the contents that emerge from the cancer survivor. Similarly, in a systematic review and meta-analysis of efficacy of available psychological interventions for FCR, Tauber et al. [33] suggested tailoring interventions focusing on the individual's FCR symptoms. Specifically, medical personnel and therapists could receive training to address unhelpful cognitive content, including appraisals, cancer beliefs and concerns that trigger distress and/or maladaptive coping. Accordingly, they could also suggest tools for increasing tolerance for uncertainty, and to facilitate effective communication with significant others and health care providers which might decrease socially constraining responses from others. Also, as death anxiety was found to underlie FCR, Cognitive-Existential intervention for FCR could be applied [e.g., 32].

\section{Conclusions}

The results of this qualitative analysis identified intra and interpersonal processes that clarify the meaning of FCR in cervical cancer survivors. In addition, FCR found to be a phenomena encompassing three factors - uncertainty, social-cognitive processing and death anxiety, which recommended to be addressed in order to promote cervical cancer survivors' wellbeing. Further qualitative studies on FCR are 
needed as the quantitative measurement of FCR might be insufficient to represent the multidimensional meaning of this phenomena.

\section{Declarations}

Funding: The authors received no financial support for the research, authorship, and/or publication of this article.

Conflicts of interest/Competing interests: The authors declare no potential conflicts of interest with respect to the research, authorship, and/or publication of this article.

Availability of data and material: Not applicable

Code availability: Not applicable

Authors' contributions: YHR, SAS and IL contributed to the study conception and design performed the recruitment and the data analysis. The first draft of the manuscript was written by YHR, and SAS and all authors reviewed and edited the manuscript. All authors read and approved the final manuscript.

Ethics approval: The study was conducted in accordance with the approval of second author University's Ethics Committee (Approval no. 112003)

Consent to participate: All the participants gave their consent to participate in accordance with the Ethics approval guidelines of the University's Ethics Committee

Consent for publication: Not applicable

Corresponding author: yairahr@ariel.ac.il

\section{References}

1. World Health Organization. Cervical cancer Geneva. 2019. Available from: https://www.who.int/cancer/prevention/diagnosis-screening/cervical-cancer/en/.

2. Thewes B, Butow P, Bell M.L, Beith J, Stuart-Harris R, Grossi M, et al. Fear of cancer recurrence in young women with a history of early-stage breast cancer: a cross-sectional study of prevalence and association with health behaviours. Support Care Cancer. 2012; 20(11): 2651-2659. https://doi.org/10.1007/s00520-011-1371-x

3. Lebel S, Ozakinci G, Humphris G, Mutsaers B, Thewes B, Prins J, et al. From normal response to clinical problem: definition and clinical features of fear of cancer recurrence. Support Care Cancer. 2016; 24(8): 3265-3268. https://doi.org/10.1007/s00520-016-3272-5

4. Herschbach P, Dinkel A. Fear of Progression. In: Goerling U. eds. Psycho-Oncology: Recent Results in Cancer Research, Springer; 2014: 11-29. https://doi.org/10.1007/978-3-642-40187-9_2 
5. Hanprasertpong J, Geater A, Jiamset I, Padungkul L, Hirunkajonpan P, Songhong N. Fear of cancer recurrence and its predictors among cervical cancer survivors. J. Gynecol Oncol. 2017; 28(6): e72. https://doi.org/10.3802/jgo.2017.28.e72

6. Simard S, Thewes B, Humphris G, Dixon M, Hayden C, Mireskandari S. et al. Fear of cancer recurrence in adult cancer survivors: a systematic review of quantitative studies. J Cancer Surviv. 2013; 7(3): 300-322. https://doi.org/10.1007/s11764-013-0272-z

7. Tsai LY, Lee SC, Wang KL, Tsay SL, Tsai JM. A correlation study of fear of cancer recurrence, illness representation, self-regulation, and quality of life among gynecologic cancer survivors in Taiwan. Taiwan J Obstet Gynecol. 2018; 57(6): 846-852. https://doi.org/10.1016/j.tjog.2018.10.014

8. Otto AK, Soriano EC, Siegel SD, LoSavio ST, Laurenceau JP. Assessing the relationship between fear of cancer recurrence and health care utilization in early-stage breast cancer survivors. $J$ Cancer. 2018; 12(6): 775-785. https://doi.org/10.1007/s11764-018-0714-8

9. Leeson SC, Beaver K, Ezendam NP, Mačuks R, Martin-Hirsch PL., Miles T, et al. The future for followup of gynaecological cancer in Europe. Summary of available data and overview of ongoing trials. Eur J Obstet Gynecol Reprod Biol. 2017; 210: 376-380.https://doi.org/10.1016/j.ejogrb.2017.01.025

10. Mehnert A, Berg P, Henrich G, Herschbach P. Fear of cancer progression and cancer-related intrusive cognitions in breast cancer survivors. Psychooncology. 2009;18(12): 1273-280.

https://doi.org/10.1002/pon.1481

11. Uner FO, Korukcu O. A qualitative exploration of fear of cancer recurrence in Turkish cancer survivors who were referred for colposcopy. Health Soc Care Community. 2021,https://doi.org/10.1111/hsc.13326

12. Creswell JW, Poth CN. Qualitative Inquiry Research Methods: Choosing Among Five Approaches. 4th( .Sage; 2018 ).ed

13. Green J, Thorogood N. Qualitative methods for health research. Sage; 2004.

14. Patton MQ. Qualitative research and evaluation methods (3rd ed.). Sage; 2002.

15. Tracy SJ. Qualitative research methods: Collecting evidence, crafting analysis, communicating impact. Wiley-Blackwell; 2012.

16. Heaton J. Secondary analysis of qualitative data: An overview. Hist. Soc. Res. 2008; 33(3): 33-45.

17. Saldaña J. The Coding Manual for Qualitative Researchers. Sage; 2015.

18. Brinkman S, Kvale S. Interviews: Learning the Craft of Qualitative Research Interviewing. (3rd ed.) Sage; 2015.

19. Mahendran R, Liu J, Kuparasundram S, Simard S, Chan YH. Kua EH, et al. Fear of cancer recurrence among cancer survivors in Singapore. Singapore Med J. 2020; 10.11622/smedj.2020007.

20. Mishel MH. Uncertainty in illness. J. Nurs. Scholarsh. 1988; 20(4): 225-232. https://doi.org/10.1111/j.1547-5069.1988.tb00082.x

21. Lepore S J. A social-cognitive processing model of emotional adjustment to cancer. In A. Baum \& B. L. Andersen (Eds.), Psychosocial interventions for cancer. American Psychological Association; 
2001: 99-116. https://doi.org/10.1037/10402-006

22. Lepore S J, Revenson TA. Social constraints on disclosure and adjustment to cancer. Soc Personal Psychol Compass, 2007; 1(1): 313-333.https://doi.org/10.1111/j.1751-9004.2007.00013.x

23. Carpenter KM, Fowler JM, Maxwell GL, Andersen BL. Direct and buffering effects of social support among gynecologic cancer survivors. Ann Behav Med. 2010;39(1):79-90. doi:10.1007/s12160-0109160-1

24. Myers SB, Manne SL, Kissane DW, Ozga M, Kashy,DA, Rubin S, et al. Social-cognitive processes associated with fear of recurrence among women newly diagnosed with gynecological cancers. Gynecol Oncol. 2013; 128(1): 120-127. https://doi.org/10.1016/j.ygyno.2012.10.014

25. Wijayanti T, Afiyanti Y, Rahmah H, Milanti A. Fear of cancer recurrence and social support among Indonesian gynecological cancer survivors. Arch Oncol. 2018; 24(2): 12-19. doi:10.2298/A00180201004W

26. Kim Y, Carver CS, Spillers RL, Love-Ghaffari M, Kaw CK. Dyadic effects of fear of recurrence on the quality of life of cancer survivors and their caregivers. Qual Life Res. 2012; 21(3): 517-525. http://doi: 10.1007/s11136-011-9953-0.

27. Soriano EC, Pasipanodya EC, LoSavio ST, Otto AK, Perndorfer C, Siegel SD. Et al. Social constraints and fear of recurrence in couples coping with early-stage breast cancer. Health. 2018; 37(9): 874884. https://doi.org/10.1037/hea0000649

28. Thewes B, Lebel S, Seguin Leclair C, Butow P. A qualitative exploration of fear of cancer recurrence (FCR) amongst Australian and Canadian breast cancer survivors. Support Care Cancer. 2016; 24(5): 2269-2276. https://doi.org/10.1007/s00520-015-3025-x

29. Tang PL, Chiou CP, Lin HS, Wang C, Liand SL. Correlates of death anxiety among Taiwanese cancer patients. Cancer Nurs. 2011; 34(4): 286-292. https://doi.org/10.1097/NCC.0b013e31820254c6

30. Sharpe L, Curran L, Butow P, Thewes B. Fear of cancer recurrence and death anxiety. Psychooncology. 2018; 27(11): 2559-2565. https://doi.org/10.1002/pon.4783

31. Pyszczynski T, Solomon S, Greenberg J. Chapter one-thirty years of terror management theory: from genesis to revelation. Adv Exp Soc Psychol. 2011; 52: 1-70 https://doi.org/10.1016/bs.aesp.2015.03.001

32. Tomei C, Lebel S, Maheu C, Mutsaers B. Addressing fear of recurrence: improving psychological care in cancer survivors. Support Care Cancer. 2016; 24(7): 2815-2818..doi: 10.1007/s00520-016-3103-8

33. Tauber NM, O'Toole MS, Dinkel A, Galica J, Humphris G, Lebel S, et al. Effect of Psychological intervention on fear of cancer recurrence: A systematic review and meta-analysis. J. Clin Oncol. 2019; 37(31): 2899-2915. https://doi.org/10.1200/JC0.19.00572 .

\section{Figures}




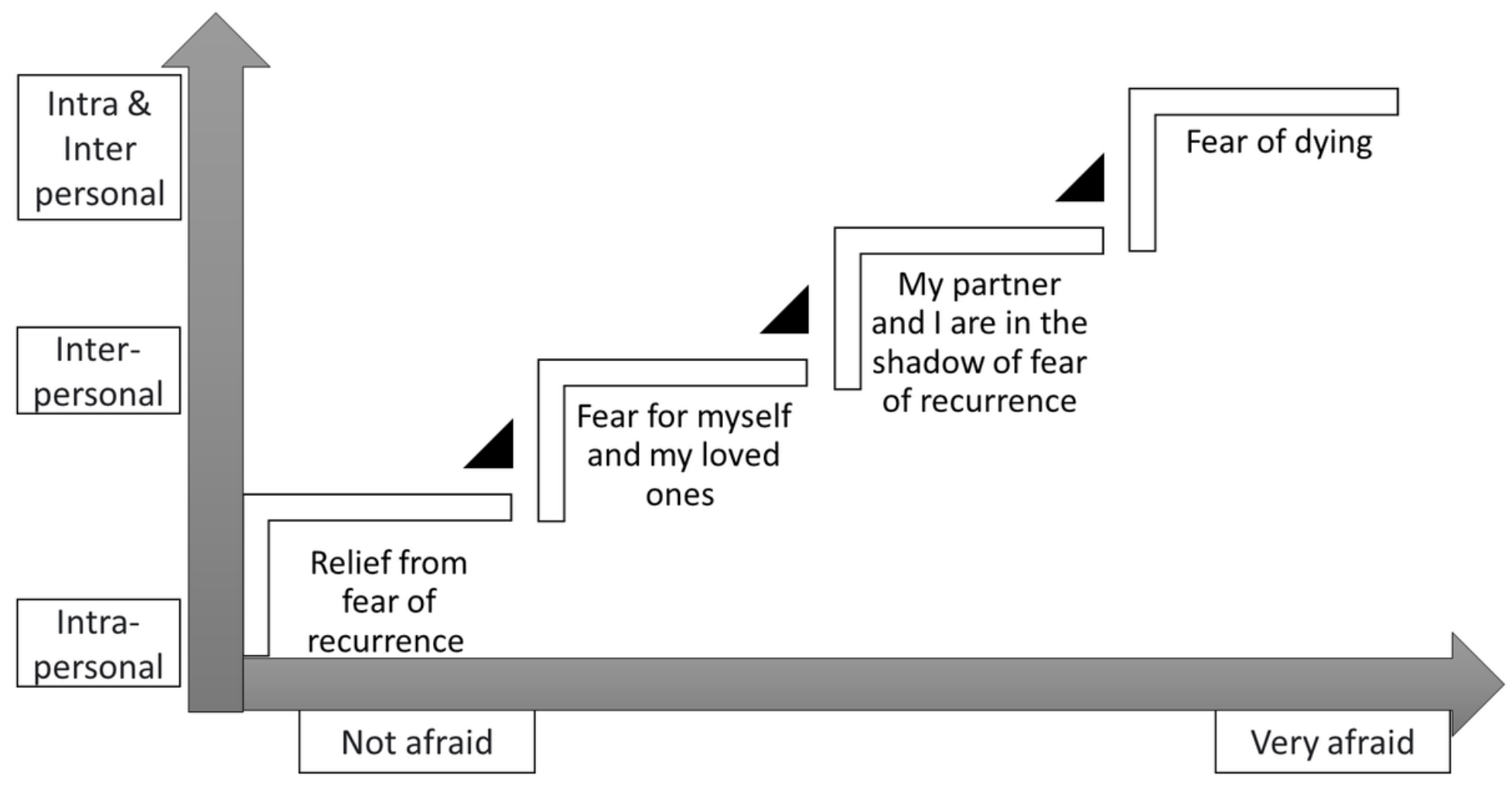

Figure 1

Themes of the meaning of fear of recurrence of cervical cancer survivors 